\title{
Research on Development Ideas of Customer-side Energy Internet Business of Power Grid Enterprises Based on SWOT Analysis Method
}

\author{
CHAI Yufeng ${ }^{1, a}$, LI Zhenwei ${ }^{2}$ and ZHAO Luxin ${ }^{2}$ \\ ${ }^{1}$ State Grid Energy Research Institute Co., LTD, Beijing, 102209. \\ ${ }^{2}$ Power supply grid enterprises of Xiong'an New Area of State Grid Hebei Electric Power Co., Ltd., Xiong'an, Hebei, China.
}

\begin{abstract}
In recent years, the concepts and practices of smart cities and "Internet plus" smart energy have mushroomed, greatly promoting the development and application of customer-side energy Internet business and stimulating users' diversified and personalized demand for interactive services of intelligent power utilization. Intelligent power utilization, as the core of the interactive service system, serves as a bridge between power supply departments and customers. Its construction has a direct impact on the efficiency, economic operation and orderly electricity consumption of power grids. In the context of the increasingly intelligent power grid and complex load structure, this paper analyzed the development trend of energy Internet and adopted SWOT to reveal the strengths, weaknesses, opportunities and challenges of power grid enterprises in developing energy Internet, explore their development ideas on energy Internet businesses, and facilitate their development of energy Internet.
\end{abstract}

\section{INTRODUCTION}

In recent years, the concepts and practices of smart cities and "Internet plus" smart energy have mushroomed, greatly promoting the development and application of intelligent power utilization business and stimulating users' diversified and personalized demand for interactive services of intelligent power utilization. Intelligent power utilization, as the core of the interactive service system, serves as a bridge between power supply departments and customers. Its construction has a direct impact on the efficiency, economic operation and orderly electricity consumption of power grids. In the context of the increasingly intelligent power grid and complex load structure, the analysis of energy Internet business of power grid enterprises is conducive to further clarifying the development direction of intelligent power utilization business, promoting the business transformation and development of power grid enterprises, and realizing the high-quality development of power grid business.

\section{DEVELOPMENT TREND OF ENERGY INTERNET}

The integrative development of energy system and information technology in the new situation has brought about three trends of energy Internet development.

Trend 1 focuses on new energy sources, pursues clean, low-carbon, safe and efficient energy sources and realizes clean development and efficient application.
Trend 2 integrates Internet concepts and technologies, breaks down multiple barriers for energy development and utilization through the construction of various networks such as facility Internet, industrial/industrial Internet, consumer Internet, etc., and realizes multiregional and multi-level interconnection of energy, facilities, information, market, social relations and other elements.

Trend 3 puts users first, creates comprehensive value, realizes two-way interaction between supply and demand from source-network-load-storage, provides energy complementation of multiple energy types and systems, and achieves value creation of business flow, information flow and energy flow ${ }^{1}$.

\section{SWOT analysis of customer-side energy Internet business}

\subsection{SWOT}

SWOT, a comprehensive analysis method, analyzes internal factors and studies external factors and carries out research based on the internal and external conditions of power grid enterprises. In SWOT, strengths, weaknesses, opportunities and challenges of the research subject are collected through a survey and arranged in a matrix. Then, various factors are matched and analyzed in a systematic manner so as to draw a range of conclusions for decision-making.

a Corresponding author: chaiyufeng@sgeri.sgcc.com.cn 


\subsubsection{Strengths}

Strengths refer to the advantages or qualities of an organization, including favorable competitive situation; abundant financial resources; good corporate image; technical strength; economies of scale; product quality; market share; cost advantage; advertising campaigns, etc.

\subsubsection{Weaknesses}

Weaknesses refer to weak links in the organization, including aging equipment; confused management; lack of key technologies; backward research and development; shortage of funds; bad management; poor competitiveness.

\subsubsection{Opportunities}

Opportunities are factors that play a positive role in the development of the organization, including new products; new markets; new demands; removal of barriers in foreign markets; competitors' mistakes, etc.

\subsubsection{Challenges}

Challenges are factors that threaten the development of the organization, including new competitors; changes in industrial policies; increased number of alternative products; market tightening; economic recession; changes in customer preferences; emergencies, etc.

\subsection{SWOT analysis on customer-side energy Internet business development of power grid enterprises}

The current landscape has brought about rare opportunities for the development of the energy Internet business of power grid enterprises, which boast evident first-mover advantages. However, they also face great internal and external challenges and need to address their weaknesses in enterprise operation, power grid operation, emerging businesses and infrastructure ${ }^{2}$.

\subsubsection{Strengths}

As the world's largest AC/DC hybrid power grid and the world's largest super-large power grid featuring new energy grid connection, power grid enterprises are of large-scale users from all walks of life and are favored by the government and users. They have formed unique strengths in power grid operation, customer service, leading technology and emerging businesses, laying a solid foundation for their development of customer-side energy Internet services.

Automation and lean management are realized in power grid operation. Power grid enterprises have established distribution automation and equipment lean management systems and built 336 prefectural and municipal power supply service command centers, which strongly supports the lean management of main distribution network equipment. Besides, a technical service platform has been set up to facilitate direct medium and long-term electricity trading.

Power grid enterprises are deeply trusted by the government and users. Power grid enterprises carry out business operations in 26 provinces (autonomous regions and municipalities directly under the Central Government) and supply power to a population of over 1.1 billion, covering various user entities such as governments, institutions, enterprises and individuals and collecting massive data assets. Moreover, electricity consumption information of about 471 million customers nationwide has been collected online, and electricity affairs handling and purchase services have been conducted online through portal websites, mobile phones, 95598 and other channels. The Online State Grid has been put into pilot operation, with the online payment rate exceeding $50 \%{ }^{3}$.

Innovations are made in key technical fields. Power grid enterprises released the Construction Outline of Ubiquitous Electric Internet of Things ("UEIOT"), formulated the research framework of UEIOT shutdown technology, focused on more than 20 basic, forwardlooking and strategic key technologies such as intelligent sensors and intelligent terminals, and enhanced collaborative services of Source-Network-Load-Storage in electric vehicles and distributed new energy sources, household intelligent energy use, community multienergy supply, energy efficiency improvement in commercial buildings, energy efficiency improvement in industrial enterprises and the whole region, etc.

Emerging businesses are widely expanded. Power grid enterprises have engaged in new business fields such as electric vehicles, integrated energy Internet and photovoltaic cloud, and have actively expanded the market. Over 820,000 charging poles have been connected to the car networking, providing one-stop services including electric vehicle sales, charging and payment.

\subsubsection{Weaknesses}

Currently, there are some weaknesses in the construction and application of customer-side energy Internet, which are mainly reflected in enterprise operation, power grid operation, emerging businesses and infrastructure.

In terms of enterprise operation, power grid enterprises, hindered by the deep-rooted system and mechanism defects, are plagued by professional barriers, low data transparency, poor data sharing and poor data utilization and analysis. Besides, more customers should be encouraged to participate in friendly electricity consumption and supply-demand integration and their satisfaction needs to be improved.

In terms of power grid operation, enterprises fail to demonstrate their ability to optimize wide-range and large-scale energy allocation and are short of flexible clean energy consumption and trading mechanism.

In terms of emerging businesses, their new businesses have not yet formed a large-scale and systematic development trend. In the absence of marketoriented management mode and Internet thinking, 
enterprises cannot satisfy the needs of customers and make timely adjustments. Moreover, they are not capable of integrating social resources and fail in sharing and cooperating with the outside world.

In terms of infrastructure, efforts should be made to further develop the plug and play technology and the connectivity technology of customer-side energy Internet business. Besides, enterprises need to realize full coverage of terminal acquisition and monitoring and formulate unified planning and design standards; enhance coverage of the communication access network, improve the utilization rate of platform software and hardware resources, handle data transmission, processing and application flexibility, and strengthen quick response to changes in customer demands ${ }^{4}$.

\subsubsection{Opportunities}

In the context of innovation and breakthrough of key technologies, promotion of the Internet economy, introduction of reforms to the electricity market and reforms to streamline administration and delegate power, improve regulation, and upgrade services, the whole industry and market players have ushered in greater opportunities, which has played a positive role in promoting the development of customer-side energy Internet business of power grid enterprises.

The progress of key technologies has laid a sound foundation for business development. The continuous progress of wind power, photovoltaic and grid-connected technologies has greatly reduced the cost of wind power and photovoltaic power generation and effectively improved conversion efficiency, providing a technical basis for the development of distributed power generation, virtual power plants, microgrid and other fields. With the further development of energy storage technology, the battery cost continues to drop and the energy density continues to increase, promoting the application of energy storage on the power supply side and the load side, and providing a vital guarantee for the development of electric vehicle charging, car networking platform, demand-side response, power grid peak regulation and frequency modulation services, etc. Information and communication technology, big data, cloud computing, IoT, blockchain, edge computing and other technologies have been continuously broken through. Data processing, storage and management capacities have been greatly improved, which is conducive to fully exploiting information value and data resources, analyzing user behaviors ${ }^{5}$, and providing technical support for the development of energy contract management, personalized customization services, and financial services such as Vertcoin.

The vigorous development of the Internet economy has put forward new paradigms and new thinking for the business development of power grid enterprises. "Internet plus" has brought about a subversive impact on the traditional retail industry, service industry and other tertiary industries. The integrative development of the Internet and the power grid has revealed new thinking and new paradigm, allowing power grid enterprises to innovate their business models. First of all, Internet thinking changes the traditional thinking mode of power grid enterprises. The Internet's user thinking, extreme thinking, big data thinking, platform thinking and crossborder thinking provide new thinking for power grid enterprises to improve product quality, expand service scope and broaden service channels. Secondly, the "Internet plus" power grid promotes business model innovation. Internet platform provides new service technologies, channels and content forms for service innovation of power grid enterprises. Using Internet thinking, these enterprises may build a way of thinking to review the market, users, products, value chains and even the entire business ecology. They may put customers first, explore customer needs, and make use of their strengths such as "data assets" to innovate business growth models and build a new collaborative and sustainable business system; effectively promote multiparty participation and redefine the value production, transmission and realization of power grids.

The reform of the electricity market will liberalize the electricity rationing business in an orderly manner and further invigorate the market. More stakeholders will participate in the market and bring new business models and marketing methods, thereby creating a favorable market environment for various flexible and diverse business model innovations. The relaxed electricity price mechanism, flexible electricity price mechanism and market mechanism provide a strong mechanism guarantee for power grid enterprises to further promote business models such as virtual power plants and demand-side response, and to realize profits and scale benefits.

Taking the reforms to streamline administration and delegate power, improve regulation, and upgrade services deployed by the Party Central Committee and the State Council as an opportunity, efforts should be made to optimize the business environment for power grid companies and power grids to achieve high-quality development. It is necessary to understand the importance of the "reforms to streamline administration and delegate power, improve regulation, and upgrade services", which are an important means for optimizing the business environment and stimulating market vitality, allowing power grid enterprises to raise the "access to electricity" index and optimize the business environment. In response to customer needs for personalized service, precise service and comprehensive service, efforts should be made to further innovate service methods, simplify business processes, speed up power connection, improve service efficiency and benefit, give full play to the characteristics of power grid enterprises, and take the lead in fulfilling the responsibilities listed by Headquarter to "streamline administration and delegate power, improve regulation, and upgrade services". Meanwhile, enterprises should make breakthroughs in key professional fields such as marketing and development, so as to properly exercise the power over all items that have been delegated to them and achieve a high-quality effect ${ }^{6}$. 


\subsubsection{Challenges}

Currently, when carrying out customer-side energy Internet businesses, power grid enterprises are facing greater challenges from external changing situations, customers' higher requirements for power services, market competition, and transformation of management concepts. Specifically, the challenges are from the following four aspects.

Customers put forward higher demands on the services of power grid companies. Under the background of transforming social contradictions in China, the Internet concept has penetrated all areas of production and life and user behavior has undergone profound changes, with more emphasis on convenience, diversity, and interaction. In this regard, power grid companies need to change their concepts, pay attention to the demands of users, and improve high-quality services.

The energy revolution is deeply integrated with technological change, and the power grid has seen significant changes. The large-scale development and utilization of new energy, the extensive access of various new energy-using equipment, and the deep integration of new energy, energy storage and other energy technologies with information technology have profoundly changed the functional form of power grids, and their operation control and resource allocation are facing a series of new requirements and challenges.

Profound changes have taken place in the reform and supervision situation, and the traditional development mode of power grid enterprises is facing challenges. The structural reform on the supply side, the reform of the power system and the reform of the state-owned assets of state-owned enterprises have been pushed forward, fundamentally changing the investment and operation modes of power grid enterprises and putting forward higher requirements for power grid enterprises to promote market-oriented transformation and realize high-quality development.

Great changes have been seen in the pattern of the energy market, and the competition situation faced by power grid enterprises becomes more severe. Efforts have been made to accelerate reform of energy marketization, lower industry barriers, introduce competition into traditional businesses and promote the rise of emerging markets. Moreover, the relatively closed pattern of energy markets is undergoing profound changes. Thus, power grid enterprises must innovate their business models and business structure, enhance their competitiveness and foster new development space ${ }^{7}$.

\section{Business development ideas of customer-side energy Internet business of power grid enterprises}

The SWOT analysis of customer-side energy Internet business of power grid enterprise is helpful to clarify their business development ideas and further provide direction for their business development framework.

\subsection{User-centered intelligent development}

A single user is of small capacity and can hardly participate in the electricity market alone. It is necessary to pool user resources to participate in electricity market trading, carbon market trading, etc. Thus, based on the core needs of users for economy and convenience, efforts should be made to provide users with energy consumption information, assist them in energy consumption management, and stimulate their interest in participating in intelligent electricity consumption.

\subsection{Electricity-based resource integration}

Intelligent electricity consumption is the window for power grids to directly serve users. Implementing the people-oriented concept of intelligent electricity consumption is always the key to improving users' stickiness under the market competition pattern. Efforts should be made to uphold Internet thinking and new economy thinking and innovate business development mode in a bid to form a new pattern centered on electricity and featuring intelligent development. Efforts should also be increased to provide services other than electricity supply, such as providing energy efficiency management services for individuals and enterprises based on big data technology.

\subsection{Data-dominated interaction}

Relying on the electricity IoT technology, sensors are widely arranged at power terminals to fully perceive power consumption data, accelerate the flow of massive perceived information through power information network, Internet, etc., and analyze and mine massive data based on cloud computing and big data technology so as to realize the interaction between power grids and customer energy flow, information flow and business flow, thus facilitating flexible access of intelligent new equipment and responding to users' free power consumption demand.

\subsection{Demand-oriented policy implementation}

According to the difference in electricity price, users can generally be divided into industrial users, commercial users and residential users. Industrial users include high energy-consuming enterprises, industrial parks and general industries. Commercial users include high-end commercial users and general commercial users. Residents include high-end residents and ordinary residents. Different types of users have different needs for electricity and energy consumption. Thus, it is necessary to analyze users' concerns and perform pertinent businesses ${ }^{8}$.

\subsection{Cooperation-based integration}

Internally, through the market mechanism, all directly affiliated industrial units and research and development units of power grid enterprises should work together to 
improve technological research and development capacity and industrial production capacity. Externally, efforts should be made to actively strive for policy support and strengthen cooperation with governments at all levels; cooperate with energy service providers, big data power grid enterprises, Internet enterprises and other industry-related parties during operation and construction.

\subsection{Technology-aided and innovation-led development}

The business development of customer-side energy Internet cannot be separated from breakthroughs and innovations in key technologies. Efforts should be made to realize breakthroughs in key technologies such as energy interaction and plug and play technology for energy supply and use, connectivity technology for energy supply and use equipment, data value-added service technology, AI, comprehensive utilization and optimization of energy, and enhance innovation and leadership of technology. Through the integration of technological innovation and demonstration applications, users may carry out friendly interaction with power grids, which will greatly improve users' experience and sense of acquisition and promote the maturity and progress of key technologies on the customer-side energy Internet.

\section{Conclusions}

Energy Internet focuses on new energy, integrates Internet concepts and technologies, puts users first, realizes two-way interaction between supply and demand from Source-Network-Load-Storage, provides energy complementation of multiple energy types and systems, and realizes value creation of business flow, information flow and energy flow. It is characterized by ubiquitous interconnection, intelligent interaction, multi-energy complementation, open collaboration, etc. In the context of energy Internet, power grid enterprises have ushered in a rare opportunity for their customer-side energy Internet business, boasting evident first-mover advantages. However, they also face great internal and external challenges, and need to address their weaknesses in enterprise operation, power grid operation, emerging businesses and infrastructure. Power grid enterprises should take users as the center, electricity as the base, data as the foundation, demand as the orientation, cooperation as the bridge, and technology as the support so as to obtain inexhaustible power for their development of energy Internet.

\section{Acknowledgments}

This work is supported by Management Consulting Project of SGCC (Research on Enterprise Development Management Mechanism and Operation Mode Based on the Energy Internet Planning and Construction of State Grid Xiong'an New Area Electric Power Supply Company)

\section{References}

1. FAN Deming, ZHU Qi. Exploration of Energy Internet Development Strategy Based on PESTSWOT Analysis [J]. Industrial \& Science Tribune, 2020, 19 (18): 14-15.

2. LI Junpeng. Application of SWOT Analysis in Strategic Management of Enterprises [J]. Business News, 2020, (25): 93-95.

3. MIAO Ying. Research on the Development Strategy of State Grid XA Power Supply Grid Enterprises [D]. Xi'an University of Technology, 2020.

4. XIN Yi, YAN Zheng, WEI Xuehao, etc. PJM Power Grid Demand Response Model and Its Enlightenment [J]. Electric Power, 2015, 48 (4): 113-120.

5. WANG Junlong, RUAN Li, XU Bin. Germany's Demand Side Resource Utilization Model and Its Enlightenment to China [J]. Power Demand Side Management, 2017, 19 (2): 61-64.

6. ZHANG Mingzhuang. Modeling and Analysis of Real-time Electricity Price Based on Demand Side Response [D]. Jiangsu University, 2017.

7. MA Yuanxin. Design of Power Demand Response Use Cases for Global Energy Internet [D].North China Electric Power University (Beijing), 2017.

8. HUANG Tian. Research on Business Operation Mode of Power Demand Response for Smart Grid [D]. Southeast University, 2016. 